\title{
Too much of a good thing: compulsive exercise in children and adolescents with eating disorders
}

\author{
Pam Formby ${ }^{1}$, Hunna J Watson ${ }^{2,3,4^{*}}$, Anna Hillyard ${ }^{5}$, Kate Martin ${ }^{6}$, Sarah J Egan ${ }^{4}$, Nine Smith-Birch ${ }^{6}$ \\ From 2015 ANZAED Conference: Riding the Waves to Recovery \\ Surfers Paradise, Australia. 21-22 August 2015
}

Compulsive exercising is the most common compensatory behaviour amongst children and adolescents with eating disorders. The Compulsive Exercise Test is a self-report measure that has been recently developed to assess the cognitive, behavioural and affective features of compulsive exercise. The aim of the current study was to validate the measure using a paediatric eating disorder sample presenting for treatment at a specialist eating disorder service.

Confirmatory factor analysis was conducted and correlations with eating disorder symptoms were examined. The study failed to confirm a factor structure, although there was still clear evidence of the multidimensionality of the measure. CET scores were significantly related to measures of eating pathology, perfectionism and exercise frequency to control shape and weight. This suggests a need for further investigation into the construct of compulsive exercise in clinical populations, given the strong association with eating pathology.

\footnotetext{
Authors' details

'School of Physiotherapy, University of Notre Dame, Fremantle, Australia. 2Department of Psychiatry, The University of North Carolina at Chapel Hill, Chapel Hill, NC, USA. ${ }^{3}$ School of Paediatrics and Child Health, The University of Western Australia, Perth, Australia. ${ }^{4}$ School of Psychology and Speech Pathology, Curtin University, Perth, Australia. ${ }^{5}$ Complex Pain Service, Princess Margaret Hospital for Children, Perth, Australia. 'Eating Disorders Program, Specialised Child and Adolescent Mental Health Service, Perth, Australia.
}

Published: 23 November 2015

doi:10.1186/2050-2974-3-S1-054

Cite this article as: Formby et al:: Too much of a good thing:

compulsive exercise in children and adolescents with eating disorders. Journal of Eating Disorders 2015 3(Suppl 1):O54.

\footnotetext{
* Correspondence: hunna_watson@med.unc.edu

2Department of Psychiatry, The University of North Carolina at Chapel Hill, Chapel Hill, NC, USA

Full list of author information is available at the end of the article
}

Submit your next manuscript to BioMed Central and take full advantage of:

- Convenient online submission

- Thorough peer review

- No space constraints or color figure charges

- Immediate publication on acceptance

- Inclusion in PubMed, CAS, Scopus and Google Scholar

- Research which is freely available for redistribution 